\title{
Stroke in Young Patients - A New Trend in Nepalese Perspective?
}

\section{Pokharel BR*, Kharel G, Thapa LJ and Rana PVS}

Department of Neurology, DM Neurology Faculty, KUMS, Nepal

\begin{abstract}
Background: Stroke is caused by the loss of blood supply to the brain, commonly known as cerebral vascular accident (CVA). Strokes in younger people (below 45 years) are not common as it usually occurs in the middle-aged and elderly. The absolute definition of stroke in young does not exist, however conventionally "young stroke" is considered for people below 45 years.
\end{abstract}

Objective: To analyse the trends in occurrence, risk factors, etiology and neuroimaging features of ischemic stroke in young adults.

Methods: In this study the records of 281 strokes patients were reviewed, out of which 33 were young patients admitted to Neurology ward of College of Medical Sciences, Bharatpur, Nepal from $1^{\text {st }}$ January to $31^{\text {st }}$ December 2013. The records were analysed on the basis of age, sex, hypertension (HTN), body mass index (BMI), smoking habits, haemoglobin $(\mathrm{Hb})$, diabetes mellitus $(\mathrm{DM})$, lipid profile, atrial fibrillation $(\mathrm{AF})$ and vascular territory with clinical and radiological evidences.

Results: Most of the young stroke patients were between $40-45$ years. Ischemic stroke was noted in $87.8 \%$ and haemorrhagic stroke was noted in $12.2 \%$ of patients. Middle cerebral artery (MCA) ischemia was noted in $57.6 \%$ of patients and anterior cerebral artery (ACA) ischemia was noted in $3 \%$ of patients. Multiple infarcts were noted in $9.1 \%$ of patients. About half of them were smoker, hypertension $42.4 \%$, diabetes mellitus $18.2 \%$ and $9.1 \%$ had atrial fibrillation.

Conclusion: The stroke is also seen in young people below 45 years. The common risk factors like smoking, Hypertension and Diabetes are increasingly recognized in young patients.

Keywords: Young stroke; Risk factors

\section{Introduction}

Stroke is caused by lack of blood supply to the brain Stroke is the second most common cause of death and major cause of disability worldwide [1]. Middle-aged group are commonly affected by stroke. Stroke consequences with respect to quality of life and ability to work especially in younger age are often poor. We don't have the data of stroke in young patients from Nepal. The National Survey of Stroke revealed that only $3.7 \%$ of all CVA that occurred in patients aged between $15-45$ years [2].

The absolute definition of stroke in young patients doesn't exist, however conventionally "young stroke" is considered for people below 45 years old. This article tries to identify types, risk factor and distributions of stroke in patients below 45 years of age.

\section{Subjects and Methods}

The medical records of the patients with the diagnosis of stroke admitted to the Neurology ward at the College Medical Sciences Bharatpur, Nepal from $1^{\text {st }}$ January 2013 to $31^{\text {st }}$ December 2013. The diagnosis of stroke was made in these patients as WHO [3].

The total numbers of patients admitted with diagnosis of stroke during the mentioned period were 281 and out of which 33 were young patients. The records of these 33 patents were analyzed to identify age, sex, and hypertension, Body mass index, smoking habits, hemoglobin, diabetes mellitus, lipid profile, atrial fibrillation and vascular territory on the basis of clinical and radiological evidences.

The data were analyzed the data using SPSSV 20.

\section{Results}

A total of 33 young patients were admitted during the mentioned period.
Baseline characteristics of the stroke patients below $45 \mathrm{yrs}$, from medical record (Tables 1, 2 and 3) Figure 1.

\section{Discussion}

Stroke is one of the major causes of disability worldwide [1]. Furthermore, stroke in young patient will have much more impact in

\begin{tabular}{|c|c|}
\hline Particulars of the patients & Characteristic features \\
\hline Age & $18-45 \mathrm{yrs}$ \\
\hline Sex & M:F; $15: 18$ \\
\hline Systolic Blood Pressure & $134 \pm 27 \mathrm{mmHg}$ \\
\hline Diastolic Blood pressure & $84.55 \pm 18 \mathrm{~mm} \mathrm{Hg}$ \\
\hline Pulse & $76.9091 \pm 9 \mathrm{beats} / \mathrm{min}$ \\
\hline Height & $1.5624 \pm 0.138 \mathrm{~cm}$ \\
\hline Weight & $58.18 \pm 101 \mathrm{~kg}$ \\
\hline Body mass index & $23.32 \pm 4.54 \mathrm{~kg} / \mathrm{m}^{2}$ \\
\hline Haemoglobin & $12.82 \pm 2.59 \mathrm{gm} / \mathrm{dl}$ \\
\hline
\end{tabular}

Table 1: Baseline characteristic of patient with stroke below $45 \mathrm{yrs}$ of age. Mean Systolic Blood pressure $134 \pm 27.62 \mathrm{mmHg}$. Mean Diastolic Blood Pressure 84.55 $\pm 18.8 \mathrm{mmHg}$, Pulse means $76.9091 \pm 9.02$ beats $/ \mathrm{min}$, Height means $1.5624 \pm$ $0.138 \mathrm{~cm}$, Average weight $58.18 \pm 10.1 \mathrm{~kg}$, Body Mass Index mean $23.32 \pm 4.54$ $\mathrm{Kg} / \mathrm{m}^{2}$ was observed.

${ }^{*}$ Corresponding author: Pokharel BR, Department of Neurology, DM Neurology Faculty, Kathmandu University School of Medical Sciences, Kavre, Nepal, Tel: 9841929745; E-mail: drbrpokh@gmail.com

Received May 23, 2015; Accepted June 20, 2015; Published June 25, 2015

Citation: Pokharel BR, Kharel G, Thapa LJ, Rana PVS (2015) Stroke in Young Patients - A New Trend in Nepalese Perspective? J Nutr Disorders Ther S1: 001. doi:10.4172/2161-0509.S1-001

Copyright: @ 2015 Pokharel BR, et al. This is an open-access article distributed under the terms of the Creative Commons Attribution License, which permits unrestricted use, distribution, and reproduction in any medium, provided the original author and source are credited. 


\begin{tabular}{|c|c|c|}
\hline Risk factors & Frequency & Percentage \\
\hline Smoking & 16 & $48.5 \%$ \\
\hline Diabetes Mellitus & 6 & $18.2 \%$ \\
\hline Hypertension & 14 & $42.2 \%$ \\
\hline Triglycerides $>150$ & 12 & $36.4 \%$ \\
\hline High Density Lipoprotein $<40$ & 17 & $51.5 \%$ \\
\hline Atrial fibrillation & 3 & $9.10 \%$ \\
\hline
\end{tabular}

Table 2: Risk factors distribution. Smoker 16 (48.5\%), Diabetes Mellitus $6(18.2 \%)$ Hypertension $14(42.4 \%)$ Triglycerides $>150=12(36 \%)$, High density lipoprotein $1-39=17(51.5 \%)$, Atrial Fibrillation $3(9.1 \%)$

\begin{tabular}{|c|c|c|}
\hline Areas of Brain & Frequency & Percentage \\
\hline Ischemic Middle Cerebral Artery & 19 & $57.6 \%$ \\
\hline Ischemic Anterior Cerebral Artery & 1 & $3 \%$ \\
\hline Ischemic brain stem & 3 & $9.1 \%$ \\
\hline Ischemic Cerebellum & 2 & $6.1 \%$ \\
\hline Thalamic infract & 1 & $3 \%$ \\
\hline Multiple infract & 3 & $9.1 \%$ \\
\hline Basal ganglia Bleed & 2 & $6.1 \%$ \\
\hline Brainstem Bleed & 2 & $6.1 \%$ \\
\hline
\end{tabular}

Table 3: Distribution of stroke according to arterial supply. Ischemic stroke were $87.8 \%$, Middle Cerebral Artery ischemia 19 (57.6\%), Anterior Cerebral Artery ischemia $1(3 \%)$, Brain stem ischemia $3(9.1 \%)$, Cerebellar Ischemia $2(6.2 \%)$ Multiple infarct $3(9.1 \%)$, Thalamic infarct $1(3 \%)$, Hemorrhagic stroke were $12.2 \%$ Basalganglia bleed $2(6.1 \%)$ Brain stem bleeds $2(6.1 \%)$.

the productivity of life. The trend of stroke cases in last four decades worldwide shows that in developing countries, the rate of incidence of stroke is rapidly increasing, by almost $100 \%$. Disability due to stroke is almost seven times as much as that of developed countries which can be due to lack of sufficient resources [4].

This study includes the age limit of people who were less than 45 years old as young patient, which is similar with many other studies. However, the Helsinki Young Stroke registry examined etiology in adults less than 49 years of age [5].
In the present study female patients were more than male patents during the afore mentioned period; this can be due to indoor pollution, which females are more exposed than males in developing country like Nepal. Moreover, rheumatic heart disease is also more common in females than males.

Smoking is a well-established factor for vascular diseases. In this study, nearly half of the patients (48.5\%) were smokers. In one of study, the risk increased to six fold when population was compared with nonsmokers who had never been exposed to environmental tobacco smoke [6].

A cardiogenic cerebral embolus is one of the most common causes of stroke in the young adults, accounting for up to one third of the cases $[7,8]$. Contrary to our findings which show only $9 \%$ of cases were cardio-embolic stroke. Mitral valve disease, which accounts for a significant proportion of cardio-embolic stroke in young patients, is more common in some populations due to a high prevalence of rheumatic heart disease [9].

Hypertension is a major risk factor for vascular diseases and stroke. In our study, $42.5 \%$ of young patients had hypertension; similar with the finding published from Jerusalem that had $42 \%$ hypertension [10]. Hypertension is the most important modifiable risk factor for stroke. Likewise, diabetes mellitus was seen in $18 \%$ of our young patients. It was interesting to find that these risk factors were seen in the younger patients in Nepalese context. Louis et al. found diabetes in $27 \%$ of the ischemic non embolic stroke cases [11]. This increasing tendency of diabetes mellitus in young adults could be the result of changes in lifestyle and eating habits of the young people.

The lipids are involved in the process of atherogenesis. In present study the high-density lipid (HDL) level was less than 40 in more than half of the patients. Higher levels of HDL cholesterol were associated with a significant decrease in risk of nonfatal stroke [11].

An increased risk of cerebral infarction among young adults with conventional vascular risk factors is observed, particularly in

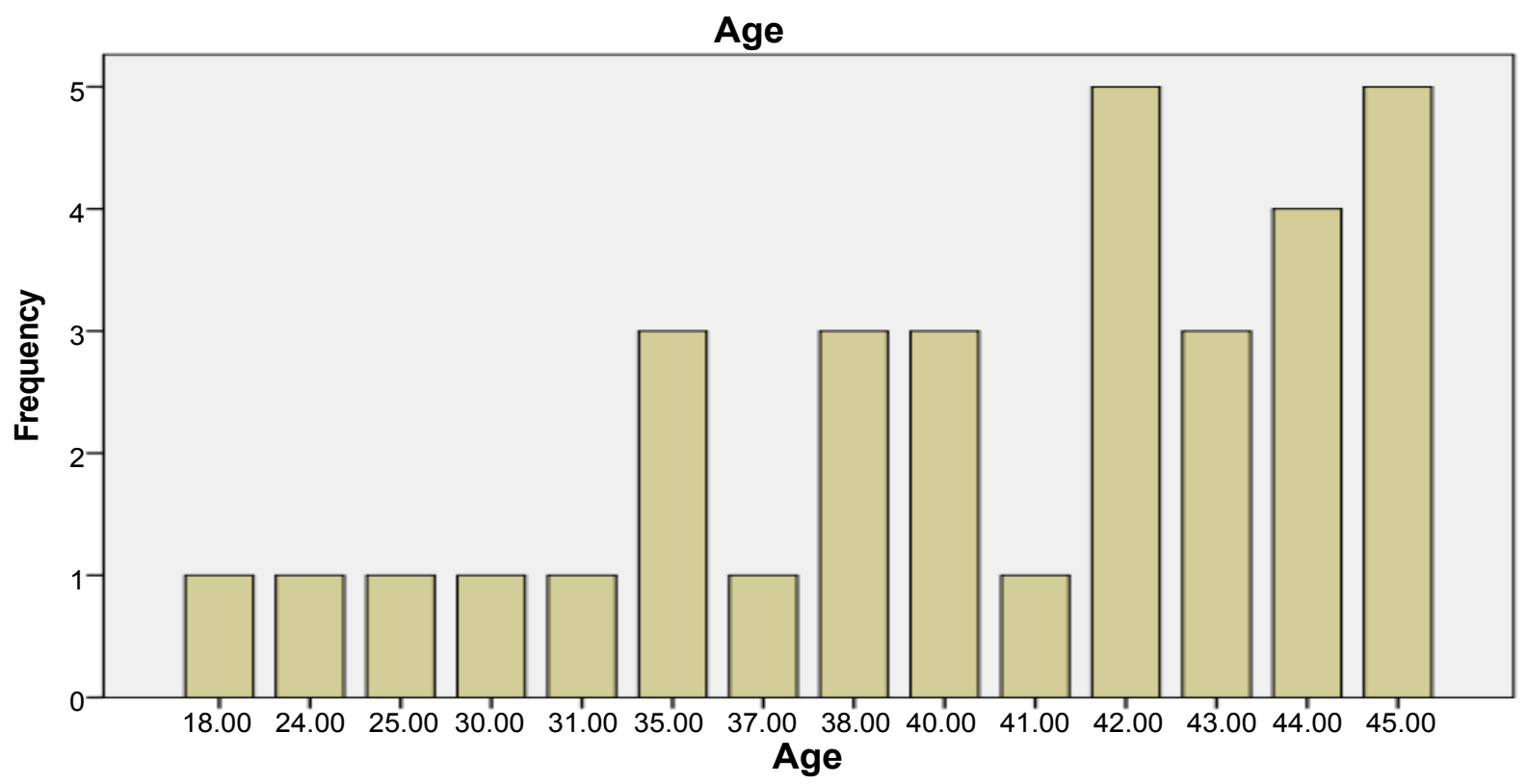

Figure 1: Age distribution of stroke patients below 45 yrs. Maximum numbers of patients were between 42 to 45 years of age. 
developing countries due to increasing smoking rates and urbanization [12]. Premature cerebral atherosclerosis is generally the result of risk factors for cerebrovascular disease such as hypertension, diabetes mellitus, and hyperlipidemia and smoking.

Atrial fibrillation (AF) is the most powerful and treatable cardiac precursor of stroke. The incidence of atrial fibrillation in our study was $9 \%$. Atrial fibrillation is associated with more severe ischemic stroke than the diseases from carotid artery [13].

The middle cerebral artery (MCA) is the largest of the intracerebral vessels and supplies through its pial branches almost the entire convex surface of the brain, including the lateral frontal, parietal, and temporal lobes ;insula; claustrum; and extreme capsule. The lenticulostriate branches of the Middle Cerebra Artery supply the basal ganglia, including the caudate, the putamen, the lateral parts of the internal and external capsules, and sometimes the extreme capsule [14].

The distributions of major ischemic s troke were in the MCA territory. In this study the middle cerebral artery infarct was $57.6 \%$. The MCA is the most common site for the occurrence of ischemic stroke. 14 Cerebral infarcts in the territory of the anterior cerebral artery (ACA) are infrequent and yet few studies have specifically assessed the clinical characteristics of stroke patients with ACA infarction [15].

In our analysis hemorrhagic strokes were $12.2 \%$. In hemorrhagic stroke, bleeding occurs directly into the brain parenchyma. The usual mechanism is thought to be leakage from small intracerebral arteries damaged by chronic hypertension. Hemorrhagic stroke is less common than ischemic stroke (i.e., stroke caused by thrombosis or embolism); epidemiologic studies indicate that only $8-18 \%$ of strokes are hemorrhagic [16].

\section{Conclusion}

Stroke in young adults is in increasing trend. The distribution of ischemic and hemorrhagic stroke is almost similar with that of adult's stroke patients. The common risk factors like smoking, hypertension and diabetes are increasingly recognized in young patients. Our study was based on a small sample. Further studies can be conducted in a larger sample to assess various other risk factors.

\section{Limitation of this Study}

The sample size is small because the stroke in younger populations of than 45 yrs is relatively rare.

\section{References}

1. Donnan GA, Fisher M, Macleod M, Davis SM (2008) Stroke. Lancet 371: $1612-$ 1623.

2. Walker AE, Robins M, Weinfeld FD (1981) The National Survey of Stroke Clinical findings. Stroke 12: I13-44.

3. Hatano S (1976) Experience from a multicentre stroke register: a preliminary report. Bull World Health Organ 54: 541-553.

4. Feigin VL, Lawes CM, Bennett DA, Barker-Collo SL, Parag V (2009) Worldwide stroke incidence and early case fatality reported in 56 population-based studies: a systematic review. Lancet Neurol 8: 355-369.

5. Putaala J, MetsoAJ, Metso TM, KonkolaN, KraemerY, et al. (2009) Analysis of 1008 consecutive patients aged 15 to 49 with first-ever ischemic stroke: the Helsinki young stroke registry. Stroke 40: 1195-1203.

6. Bonita R, Duncan J, Truelsen T, Jackson RT, Beaglehole R (1999) Passive smoking as well as active smoking increase the risk of acute stroke. Tob Control 8: 156-160

7. Hart RG, Freeman GL (1987) Stroke in young people--the heart of the matter West J Med 146: 596-597.

8. Norris J, Hachinski V (1991) Stroke Prevention: Past, Present, and Future. In Prevention of Stroke: Springer New York 1-15.

9. Ghandehari K, Moud ZI (2006) Incidence and etiology of ischemic stroke in Persian young adults. Acta Neurol Scand 113: 121-124.

10. Lavy S, Melamed E, Cahane E, Carmon A (1973) Hypertension and diabetes as risk factors in stroke patients. Stroke 4: 751-759.

11. Wannamethee SG, Shaper AG, Ebrahim S (2000) HDL-Cholesterol, total cholesterol, and the risk of stroke in middle-aged British men. Stroke 31: 1882 1888.

12. Brainin $M$, Teuschl $Y$, Kalra $L$ (2007) Acute treatment and long-term management of stroke in developing countries. Lancet Neurol 6: 553-561.

13. Anderson DC, Kappelle LJ, Eliasziw M, Babikian VL, Pearce LA, et al. (2002) Occurrence of hemispheric and retinal ischemia in atrial fibrillation compared with carotid stenosis. Stroke 33: 1963-1967.

14. O'Sullivan Susan, Thomas J (2007) Physical Rehabilitation. (5thedtn), FA Davis Philadelphia, 711-712.

15. Brust JCM, Chamorro A (2004) Anterior cerebral artery disease. Stroke. Pathophysiology, Diagnosis, and Management. Philadelphia: Churchill Livingstone; 101-122.

16. Feigin VL, Lawes CM, Bennett DA, Anderson CS (2003) Stroke epidemiology: a review of population-based studies of incidence, prevalence, and casefatality in the late 20th century. Lancet Neurol 2: 43-53. 